\title{
Asymptomatic congenital cystic adenomatoid malformation of the lung: Is it time to operate?
}

\author{
Andrea Conforti, MD, ${ }^{\mathrm{a}}$ Ivan Aloi, MD, ${ }^{\mathrm{b}}$ Alessandro Trucchi, MD, ${ }^{\mathrm{a}}$ Francesco Morini, MD, ${ }^{\mathrm{a}}$ \\ Antonella Nahom, MD, ${ }^{a}$ Alessandro Inserra, MD, ${ }^{b}$ and Pietro Bagolan, $\mathrm{MD}^{\mathrm{a}}$
}

\begin{abstract}
Objective: The optimal management of congenital adenomatoid malformation of the lung remains controversial. Prenatal ultrasonographic analysis has increasingly discovered asymptomatic lesions, raising questions about the need for and timing of surgical treatment for asymptomatic congenital adenomatoid malformation. The aim of our study was to analyze the short-term postoperative outcome of symptomatic congenital adenomatoid malformations compared with asymptomatic malformations.
\end{abstract}

\begin{abstract}
Methods: All the data of patients presenting with congenital adenomatoid malformations histologically diagnosed and operated on between 1998 and 2005 at our institution were retrospectively reviewed. Patients were divided into 2 groups: group A comprised asymptomatic infants, and group B comprised symptomatic infants. Major outcomes considered were the length of ventilation, pleural drainage, and hospital stay. Postoperative morbidity and mortality were also evaluated. Asymptomatic patients were further stratified for age at the time of the operation to evaluate whether age at surgical intervention affects the outcome. The Fisher's exact and MannWhitney tests were used as appropriate.
\end{abstract}

Results: Fifty-seven patients were consecutively treated. Thirty-five patients were given diagnoses of asymptomatic lesions and were enrolled into group A, whereas 22 patients presenting with symptoms were entered into group B. The lengths of ventilation, pleural drainage, and hospital stay were significantly longer in patients with symptomatic congenital adenomatoid malformations. Moreover, symptomatic patients presented with a higher postoperative complication rate. The age-based stratification of asymptomatic children did not show any difference on either postoperative mortality or major outcome considered.

Conclusion: Children with congenital adenomatoid malformations operated on when asymptomatic present a better short-term outcome than symptomatic children. In addition, age at the time of the operation does not negatively affect the outcome. Our findings support early surgical treatment for asymptomatic congenital adenomatoid malformation.

Congenital cystic adenomatoid malformation of the lung (CCAM) is a relatively rare developmental defect of the lung. The exact cause is not completely understood. ${ }^{1}$

CCAM is usually diagnosed prenatally by means of routine ultrasonographic analysis, is typically unilateral, and involves only a single lobe of the lung. An entire range of different clinical courses was reported for antenatally diagnosed CCAMs, varying from fetal hydrops and neonatal demise to complete prenatal spontaneous regression. ${ }^{2-7}$ Postnatal presentation is also variable as much as prenatal clinical history. ${ }^{3,4}$ Symptoms range from respiratory distress at birth with neonatal death to entirely asymptomatic lesions

\footnotetext{
From the Department of Medical and Surgical Neonatology, ${ }^{a}$ Unit of Newborn Surgery, and the Department of Surgery, ${ }^{\mathrm{b}}$ Unit of Pediatric General Surgery, "Bambino Gesu'" Children's Hospital, Rome, Italy.

Received for publication Jan 8, 2008; revisions received Dec 17, 2008; accepted for publication Jan 27, 2009; available ahead of print March 27, 2009.

Address for reprints: Andrea Conforti, MD, Department of Medical and Surgical Neonatology, “Bambino Gesu”' Children's Hospital, Rome, Italy (E-mail: anconforti@ gmail.com).

J Thorac Cardiovasc Surg 2009; 138:826-30

$0022-5223 / \$ 36.00$

Copyright (c) 2009 by The American Association for Thoracic Surgery

doi: $10.1016 /$ j.jtcvs.2009.01.014
}

discovered when incidentally performing a chest radiograph for recurrent pneumonias or spontaneous pneumothorax during adulthood.

Surgical removal of the lesion is considered the gold standard for all patients with CCAMs who became symptomatic. ${ }^{5,7-9}$ However, the management of asymptomatic lesions is still debated. Some authors advocate early intervention to prevent possible complications later in life, whereas others suggest a wait-and-see policy to avoid possible surgical complications. ${ }^{5,9,10}$

The aims of our study were to evaluate (1) whether children surgically treated for symptomatic CCAMs have a different outcome compared with those undergoing operations for asymptomatic lesions and (2) whether young age at the time of the operation negatively affects the outcome.

\footnotetext{
MATERIALS AND METHODS

Medical records of all patients with CCAMs undergoing operations from January 1988 to December 2005 were retrospectively reviewed with approval of our ethics review board. Selection criteria for the study were a histologically proved CCAM with or without accessorial vessels, as for mixed lesions. Patients affected by other lung malformations were excluded (Figure 1). Preoperative evaluation consisted of routine blood examination,
} 


\section{Abbreviations and Acronyms}

CCAM $=$ congenital cystic adenomatoid malformation of the lung

$\mathrm{CI}=$ confidence interval

$\mathrm{OR}=$ odds ratio cardiologic assessment, and chest radiographic analysis. All patients underwent a preoperative thoracic computed tomographic scan to confirm the diagnosis. All children underwent open lateral thoracotomy through the fourth or fifth intercostal space, according to the site of the lesion. Standard antibiotics were administered, and a pleural drain was inserted at the time of the operation. All specimens were histologically examined by a senior pathologist to confirm the diagnosis.

Patients were stratified according to symptomatology before the operation: group A included all children undergoing operations when asymptomatic, whereas symptomatic children were enrolled in group B. Patients were considered symptomatic when they presented with at least 1 of the following symptoms: respiratory distress syndrome, dyspnea, cyanosis with no other possible cause, recurrent pneumonia, asthmatic spells, and spontaneous pneumothorax. Table 1 summarizes the clinical characteristics of the 2 groups.

The evaluated outcomes were as follows. First were the need and length of postoperative mechanical ventilation. The need for mechanical ventilation was established by a team of expert intensivists (parameters considered to stop ventilation were a required fraction of inspired oxygen of 0.25 , a $\mathrm{PaCO}_{2}$ of less than $44 \mathrm{~mm} \mathrm{Hg}$, and a $\mathrm{PaO}_{2}$ of between 95 and $100 \mathrm{~mm}$ $\mathrm{Hg}$ ). Second were the occurrence and length of pleural drainage. Criteria consistent with pleural drainage removal were complete re-expansion of the lung and absence of pleural effusion at chest radiographic analysis 24 hours after closed drainage. Third was the length of postoperative hospital stay. Fourth was the incidence of major postoperative complications (eg, pleural effusion, hemothorax, and pneumothorax under tension). The final evaluated outcome was the mortality rate.

A subsequent age-based stratification of all asymptomatic patients was performed to assess whether age at the time of surgical intervention affects the outcome. First, we considered a cutoff limit of 6 months of age at the time of intervention because younger infants are generally considered at increased risk for perioperative complications. Subsequently, an earlier age limit at the time of the operation of 3 months was considered to better understand the role of age on outcome. Patients in group B were not restratified on the basis of age because, according to the literature, ${ }^{5,7-9}$ symptoms have to be considered an indication for surgical intervention independently from the age of the patients. Statistical analysis was performed with the Fisher's exact and Mann-Whitney tests. Calculation of odds ratios (ORs) and $95 \%$ confidence intervals (CIs) was achieved for age-related risk of symptom development.

\section{RESULTS}

\section{Asymptomatic Versus Symptomatic Patients}

Fifty-seven patients were consecutively treated from January 1998 to December 2005. Thirty-five were asymptomatic at the time of the operation (group A), whereas 22 presented with symptoms (group B). All infants enrolled in group A had a prenatal suspicion of CCAM and were evaluated throughout pregnancy up to the delivery, whereas only $8(36.3 \%)$ symptomatic patients had an antenatal diagnosis of "congenital cyst of the lung" $(P<.05)$. Five of these infants had symptoms in the first 10 days of life, 2 more before 6 months of age, and only 1 at 5 years of age. Symptoms observed were respiratory distress syndrome in 3 patients, recurrent pneumonia in 2 patients, and dyspnea and cyanosis with no other cause in 3 patients. Notably, analyzing age at the time of the operation, patients older than 6 months of age were more likely to be symptomatic at the time of the operation (OR, 5.317; 95\% CI, 1.558 18.145). At the time of the operation, all patients underwent complete lobectomy (Table 1). In a symptomatic patient operated on at 11 months of age, rhabdomyoblastic foci were found within the lesion on microscopic analysis.

The need for postoperative mechanical ventilation was similar for children enrolled in the study $(P=.78)$; however, longer sedation and mechanical ventilation were required for patients with symptomatic CCAMs compared with those with asymptomatic CCAMs $(P=.0016)$. Moreover, we found that the lengths of pleural drainage and postoperative hospital stay were significantly longer in symptomatic children $(P=.0034$ and $P=.0005$, respectively). Patients treated for symptomatic CCAMs presented with a higher rate of major postoperative complications $(P=.02)$, whereas the mortality rate did not shown any difference between the 2 groups, with only 1 death observed in a symptomatic infant undergoing an operation (right pneumonectomy) during his first day of life for intractable respiratory failure (Table 2).

\section{Analysis of Age-Stratified Asymptomatic Babies}

Patients in group A were subsequently stratified according to age at the time of the operation $(\leq 6$ or $>6$ months). Twenty-seven infants underwent surgical intervention before 6 months of age, whereas only 8 children experienced lobectomy later in life. No difference was found among those 2 groups, except for age and weight at the time of the operation. The need for and length of mechanical ventilation were similar ( $P=.33$ and $P=.42$, respectively), as was the duration of pleural drainage and the length of hospital stay $(P=.42$ and $P=.06$, respectively). No differences in complication and mortality rates were observed $(P=1.0$ in both cases). Similar results were obtained when stratifying asymptomatic babies undergoing operations before or after 3 months of age (Table 3).

\section{DISCUSSION}

CCAM is a rare congenital lesion of the lung that is usually limited to one pulmonary lobe and characterized by cystic enlargement with adenomatoid appearance of the lung parenchyma. The exact incidence in the general population is still not well defined: the only 2 population-based reports available in the literature found an incidence ranging approximately from $3 / 10^{5}$ to $9 / 10^{5}{ }^{2,11}$ Data are derived largely from tertiary care centers and might not reflect general population rates. In addition, at birth, CCAM is usually asymptomatic and might be silent for years. This noiseless clinical 


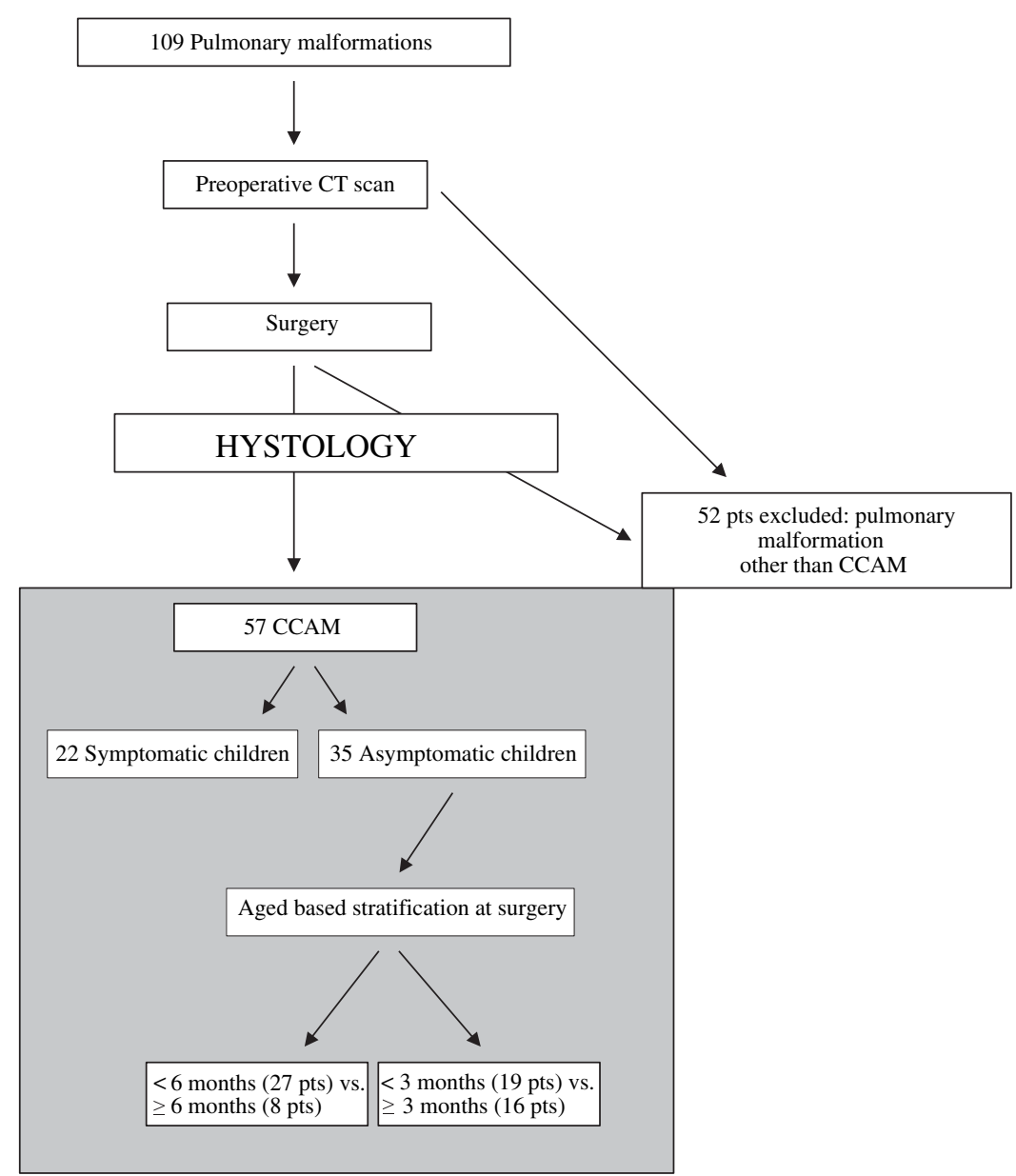

FIGURE 1. Selection flowchart. $C T$, Computed tomography; $C C A M$, congenital cystic adenomatoid malformation of the lung.

behavior might be responsible for a high rate of hidden morbidity of CCAM in the general population. Nonetheless, antenatal diagnosis is increasingly reported because of improvement in prenatal ultrasonographic screening. ${ }^{12}$ Prenatal suspicion has important consequences on maternal and fetal ongoing care. Although the prognosis is good for most of these babies, prenatal evolution of CCAMs can

TABLE 1. Patient characteristics

\begin{tabular}{|c|c|c|c|}
\hline & Group A & Group B & $P$ value \\
\hline No. of patients $(\%)$ & $35(61.4)$ & $22(38.6)$ & \\
\hline $\begin{array}{l}\text { Prenatal diagnosis, } \\
\text { n }(\%)\end{array}$ & $35(100)$ & $8(36.3)$ & $<.05$ \\
\hline Sex (male/female) & $12 / 23$ & $11 / 11$ & NS \\
\hline $\begin{array}{l}\text { Age at intervention, } \\
\text { median (range) }\end{array}$ & $213 \mathrm{~d}(1 \mathrm{~d}-5 \mathrm{y})$ & $1140 \mathrm{~d}(1 \mathrm{~d}-14 \mathrm{y})$ & $<.05$ \\
\hline $\begin{array}{l}\text { Weight at intervention } \\
(\mathrm{g}), \text { median (range) }\end{array}$ & $\begin{array}{c}6050(2480- \\
16,000)\end{array}$ & $\begin{array}{c}13,090(2070- \\
43,000)\end{array}$ & $<.05$ \\
\hline Lobectomies (right/left) & $\begin{array}{l}\text { Upper lobe: } 3 / 6 \\
\text { Middle lobe: } 1 \\
\text { Lower lobe: } 15 / 10\end{array}$ & $\begin{array}{l}\text { Upper lobe: } 5 / 5 \\
\text { Middle lobe: } 1 \\
\text { Lower lobe: } 3 / 8\end{array}$ & \\
\hline
\end{tabular}

NS, Not significant. vary widely, from complete regression to the development of fetal hydrops, which is nearly always fatal. This unpredictable course of antenatally detected CCAMs should be considered during prenatal counseling, and a close followup during pregnancy is essential to allow appropriate fetomaternal treatment. ${ }^{10}$

Delivery has to be planned in a tertiary care center only for those fetuses presenting with factors worsening the prognosis (eg, hydrops, severe mediastinal shift,

TABLE 2. Group A versus group B

\begin{tabular}{lccc}
\hline & $\begin{array}{c}\text { Group A } \\
(\mathbf{n}=\mathbf{3 5})\end{array}$ & $\begin{array}{c}\text { Group B } \\
(\mathbf{n = 2 2})\end{array}$ & $\begin{array}{c}\boldsymbol{P} \\
\text { value }\end{array}$ \\
\hline $\begin{array}{l}\text { No. of patients requiring ventilation } \\
\begin{array}{l}\text { Length of ventilation (d), median } \\
\quad \text { (range) }\end{array}\end{array}$ & 18 & 10 & .78 \\
$\begin{array}{l}\text { Length of pleural drainage (d), median } \\
\quad(\text { range) }\end{array}$ & $5(3-10)$ & $2(1-14)$ & .0016 \\
$\begin{array}{l}\text { Length of hospital stay (d), median } \\
\quad \text { (range) }\end{array}$ & $10(6-68)$ & $25.5(1-87)$ & .0005 \\
$\begin{array}{l}\text { Major complications (n) } \\
\text { Deaths (n) }\end{array}$ & 4 & 9 & .02 \\
\hline
\end{tabular}


TABLE 3. Asymptomatic patients younger than/older than 6 months and asymptomatic patients younger than/older than 3 months

\begin{tabular}{|c|c|c|c|c|c|c|}
\hline & $\begin{array}{c}\text { Group A, } \\
<\mathbf{6} \text { mo }(\mathbf{n}=27)\end{array}$ & $\begin{array}{c}\text { Group A, } \\
\geq \mathbf{6} \operatorname{mo}(n=8)\end{array}$ & $\begin{array}{c}P \\
\text { value }\end{array}$ & $\begin{array}{c}\text { Group A, } \\
<\mathbf{3} \operatorname{mo}(\mathbf{n}=19)\end{array}$ & $\begin{array}{c}\text { Group A, } \\
\geq \mathbf{3} \operatorname{mo}(\mathbf{n}=16)\end{array}$ & $\begin{array}{c}P \\
\text { value } \\
\end{array}$ \\
\hline No. of patients requiring ventilation & 14 & 4 & .33 & 9 & 9 & .73 \\
\hline Length of ventilation (d), median (range) & $1(1-2)$ & $1.5(1-2)$ & .42 & $1(1-2)$ & $1(1-2)$ & 62 \\
\hline Length of pleural drainage (d), median (range) & $5.5(4-10)$ & $4.5(3-7)$ & .42 & $6(4-10)$ & $5(3-8)$ & .12 \\
\hline Length of hospital stay (d), median (range) & $10(7-68)$ & $8.5(6-11)$ & .06 & $11(7-68)$ & $9.5(6-16)$ & .12 \\
\hline Major complications (n) & 3 & 1 & 1.0 & 3 & 1 & 61 \\
\hline Deaths (n) & 0 & 0 & 1.0 & 0 & 0 & 1.0 \\
\hline
\end{tabular}

polyhydramnios, and large lesions). ${ }^{10}$ This approach guarantees an early perinatal evaluation, an easy admission to the neonatal intensive care unit, and immediate surgical treatment when necessary.

\section{Principal Findings}

In addition to antenatal evolution, the postnatal course can be widely variable, from a complete asymptomatic lesion to life-threatening symptomatic swelling. This unpredictable behavior of CCAMs raised questions about the best surgical timing for asymptomatic babies. Symptoms are generally considered an indication for prompt CCAM surgical removal, ${ }^{5,7-9}$ whereas the debate on the timing of surgical treatment for asymptomatic patients still goes on. Our data suggest that patients treated for symptomatic CCAMs experienced a longer and more complicated postoperative clinical course. Those patients, compared with asymptomatic patients, underwent longer mechanical ventilation, pleural drainage stay, and hospitalization. Accordingly, different authors reported a similar experience. ${ }^{3,5,9,13}$ Furthermore, we found an increased risk of respiratory symptoms in babies older than 6 months (OR, 5.317; 95\% CI, 1.558 18.145). Calvert and Lakhoo 9 also found, in their series of 19 patients, a higher incidence of chronic inflammation/infection on histology in patients treated at 6 months or older. Those findings suggest performing elective surgical intervention of antenatally diagnosed CCAMs before symptoms develop. Conversely, some authors advocated conservative management for asymptomatic CCAMs, given the risks of surgical intervention and anesthesia in young children ${ }^{10}$ or reporting the development of complications in "only" $10 \%$ of asymptomatic CCAM lesions when left untreated. ${ }^{8}$ Our data demonstrate that young age at intervention (either younger than 6 or even 3 months of age) do not negatively affect postoperative outcome: asymptomatic patients undergoing operations at less than 6 or 3 months of age did not have differences in complication rate, hospital stay, and treatment required when compared with asymptomatic older patients. This is consistent with other reports, in which no increased risks were found in infants undergoing operations in their first months of life. ${ }^{5,14}$ However, the reported $10 \%$ of postoperative complications in asymptomatic patients might be considered too high to be accepted. Nonetheless, it seems that, according to current knowledge, all asymptomatic patients will undergo an operation at some point in their lives because of the development of symptoms. Consequently, all patients left untreated will experience a theoretically higher risk of major postoperative complications.

Parental psychologic distress might also be considered because it is increased by prenatal diagnosis of congenital anomalies. Repeated consultations during pregnancy have been shown to reduce parental anxiety ${ }^{15}$; however, Skari and coworkers ${ }^{16}$ found that prenatal diagnosis of congenital malformations was a significant independent predictor of acute parental psychologic distress after birth. An early surgical correction might reduce this stress and the correlated parental anxiety. Moreover, early surgical removal of asymptomatic CCAMs virtually abolishes any psychologic distress of children treated later in life. Finally, some have suggested early removal of asymptomatic lesions based on the anecdotal risk of malignancies associated with untreated CCAMs ${ }^{17} \mathrm{We}$ do not consider such an approach effective, even if the rhabdomyoblastic transformation was seen in an 11-month-old baby with a symptomatic CCAM. Nonetheless, the possible threat of malignancies later in life has to be reported to parents during prenatal or postnatal counseling.

\section{Recommendations}

CCAM lesions should be surgically treated. ${ }^{5,7-9}$ In our series babies with symptomatic CCAMs faced more postoperative complications, had a more intensive postsurgical course, and experienced a longer hospital stay. Moreover, children older than 6 months had an increased risk of becoming symptomatic. On the other hand, no major risk of complication was observed in babies operated on within 6 or even 3 months. Therefore surgical removal of asymptomatic CCAMs at the third or fourth month of age is safe, is effective, does not negatively affect the outcome, and probably reduces the parental psychologic distress. For those reasons, we suggest an early elective operation for asymptomatic CCAMs.

\section{Limitations}

This study has an intrinsic limitation because it was designed as a retrospective analysis and not as a prospective randomized trial. 


\section{References}

1. Whitsett JA, Wert SE, Trapnell BC. Genetic disorders influencing lung formation and function at birth. Hum Mol Genet. 2004;13:R207-15.

2. Gornall AS, Budd JL, Draper ES, Konje JC, Kurinczuk JJ. Congenital cystic adenomatoid malformation: accuracy of prenatal diagnosis, prevalence and outcome in a general population. Prenat Diagn. 2003;23:997-1002.

3. Adzick NS, Harrison MR, Crombleholme TM, Flake AW, Howell LJ. Fetal lung lesions: management and outcome. Am J Obstet Gynecol. 1998;179:884-9.

4. Calvert JK, Boyd PA, Chamberlain PC, Syed S, Lakhoo K. Outcome of antenatally suspected congenital cystic adenomatoid malformation of the lung: 10 years' experience 1991-2001. Arch Dis Child Fetal Neonatal Ed. 2006;91: F26-8.

5. Kim YT, Kim JS, Park JD, Kang CH, Sung SW, Kim JH. Treatment of congenital cystic adenomatoid malformation-does resection in the early postnatal period increase surgical risk? Eur J Cardiothorac Surg. 2005;27:658-61.

6. Miller JA, Corteville JE, Langer JC. Congenital cystic adenomatoid malformation in the fetus: natural history and predictors of outcome. J Pediatr Surg. 1996;31: 805-8.

7. van Leeuwen K, Teitelbaum DH, Hirschl RB, Austin E, Adelman SH, Polley TZ, et al. Prenatal diagnosis of congenital cystic adenomatoid malformation and its postnatal presentation, surgical indications, and natural history. J Pediatr Surg. 1999;34:794-9.

8. Aziz D, Langer JC, Tuuha SE, Ryan G, Ein SH, Kim PC. Perinatally diagnosed asymptomatic congenital cystic adenomatoid malformation: to resect or not? J Pediatr Surg. 2004;39:329-34
9. Calvert JK, Lakhoo K. Antenatally suspected congenital cystic adenomatoid malformation of the lung: postnatal investigation and timing of surgery. $J$ Pediatr Surg. 2007;42:411-4.

10. Sauvat F, Michel JL, Benachi A, Emond S, Revillon Y. Management of asymptomatic neonatal cystic adenomatoid malformations. J Pediatr Surg. 2003;38:548-52.

11. Laberge JM, Flageole H, Pugash D, Khalife S, Blair G, Filiatrault D, et al. Outcome of the prenatally diagnosed congenital cystic adenomatoid lung malformation: a Canadian experience. Fetal Diagn Ther. 2001;16:178-86.

12. Duncombe GJ, Dickinson JE, Kikiros CS. Prenatal diagnosis and management of congenital cystic adenomatoid malformation of the lung. Am J Obstet Gynecol. 2002;187:950-4.

13. Marshall KW, Blane CE, Teitelbaum DH, van Leeuwen K. Congenital cystic adenomatoid malformation: impact of prenatal diagnosis and changing strategies in the treatment of the asymptomatic patient. AJR Am J Roentgenol. 2000;175:1551-4.

14. Adzick NS, Flake AW, Crombleholme TM. Management of congenital lung lesions. Semin Pediatr Surg. 2003;12:10-6.

15. Aite L, Trucchi A, Nahom A, Zaccara A, La Sala E, Bagolan P. Antenatal diagnosis of surgically correctable anomalies: effects of repeated consultations on parental anxiety. J Perinatol. 2003;23:652-4.

16. Skari H, Malt UF, Bjornland K, Egeland T, Haugen G, Skreden M, et al. Prenatal diagnosis of congenital malformations and parental psychological distress-a prospective longitudinal cohort study. Prenat Diagn. 2006;26:1001-9.

17. Ozcan C, Celik A, Ural Z, Veral A, Kandiloğlu G, Balik E. Primary pulmonary rhabdomyosarcoma arising within cystic adenomatoid malformation: a case report and review of the literature. J Pediatr Surg. 2001;36:1062-5. 